\title{
Endarterektomi Yapılan Atan Kalpte Koroner Baypas Cerrahisinin Uzun Dönem Sonuçları
}

\author{
Long-Term Results of Coronary Endarterectomy in Off-Pump \\ Coronary Artery Bypass Surgery
}

\section{Özgür YILDIRIMID}

ÖY: 0000-0002-6842-135X

Yeni Yüzyıl Üniversitesi Tıp Fakultesi Kalp ve Damar cerrahisi Bölümü, İstanbul/Türkiye

\section{Özet}

Bu çalışmanın amacı, kurumumuzda koroner endarterektomi yapılan atan kalpte koroner arter baypas greft cerrahisinin geç dönem sonuçlarını gözden geçirmektir.

1996-2006 yılları arasında endarterektomi yapılan atan kalpte koroner bypass cerrahisi uygulanmıs 48 hasta incelendi. Yaş ortalaması 58,8 \pm 9,8 yl idi. Yirmi dört hasta (\%50) Kanada Kalp Derneği sınıf III veya IV idi. Yirmi sekiz hastada (\%58) sol ventrikül disfonksiyonu mevcuttu. On altı hastada (\%33) Tip 2 Diabetes Mellitus vardı.

Yirmi dokuz hastaya (\%60), sol ön inen arter endarterektomi ve 17 hastaya (\%35) sağ koroner arter endarterektomi uygulandı. Yedi hastaya (\%15) tam arteriyel revaskülarizasyon yapıldı. Erken mortalite oranı $\% 6,3(n=3)$ idi. İki hastada $(\% 4,2)$ ameliyat sonrası miyokart enfarktüsü görüldü ve 2 hastaya $(\% 4,2)$ ameliyat sonrası İntraaortik balon pom-

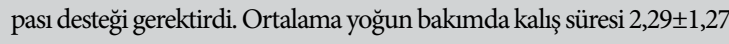
gündü. Hastalar ortalama $11 \pm 6$ saat sonra ekstübe edildi. Ortalama hastanede kalıs süresi $9 \pm 6$ gündü. Dört hastada $(\% 8,3)$ ameliyat sonrası atriyal fibrilasyon gelişti ve ameliyat sonrası ortalama $1,21 \pm 1,35$ ünite kan transfüzyonu yapıldı. Üç hasta $(\% 6,3)$ kanama revizyonuna alındı ve $4(\% 8,3)$ hastaya pozitif inotropik destek gerekti. Ortalama takip süresi 117 $\pm 4,65$ aydı ve bu sürede hastaların \%85,5'inde anjina şikâyeti olmadi. $27,2 \pm 18,32$ aylık takip periyodunda yapılan 12 kontrol koroner anjiyogram, toplam greftlerin \%85'inin açık olduğunu gösterdi.

Yaygın koroner arter hastalı̆̆ında, atan kalpte koroner arter bypass cerrahisinde gerçekleștirilen koroner endarterektomi, kabul edilebilir mortalite ve morbidite oranları ile yapılabilmektedir.

Anahtar Kelimeler: yaygın koroner arter hastalığı, atan kalp, koroner endarterektomi

\section{Abstract}

The aim of the study was to review the late term results of coronary endarterectomy in off-pump coronary artery bypass graft surgery performed in our institution

Between 1996 and 2006, 48 patients who underwent off-pump coronary artery bypass graft surgery and coronary endarterectomy were retrospectively studied. The mean age was $58,8 \pm 9,8$ years. Twenty-four patients (50\%) were Canadian Cardiovascular Society class III or IV. Twenty-eight patients (58\%) had impaired left ventricular function. Sixteen patients (\%33) had Type 2 Diabetes Mellitus.

Twenty-nine patients (60\%) underwent endarterectomy of left anterior descending artery and 17 patients (35\%) underwent endarterectomy of right coronary artery.

Seven patients (15\%) underwent full arterial revascularization. The early mortality rate was $6,3 \%(n=3)$. Two patients $(4.2 \%)$ suffered from postoperative myocardial infarction, and 2 patients (4.2\%) required postoperative intra-aortic balloon pump counterpulsation. Mean intensive care unit stay was 2,29 $\pm 1,27$ days. Patients were extubated after a mean of $11 \pm 6$ hours. The mean length of hospital stay was $9 \pm 6$ days. Four patients $(8,3 \%)$ had postoperative atrial fibrillation, and a mean of $1,21 \pm 1,35$ units of blood were transfused postoperatively. There was three $(\% 6,3)$ reopening for bleeding, and $4(\% 8,3)$ patients required positive inotropic support. The median follow-up was $117 \pm 4,65$ months, $85,5 \%$ of patients were angina free, and at the $27.2 \pm 18,32$ months follow up period 12 control coronary angiogram showed that $85 \%$ of total grafts were patent.

Coronary endarterectomy in off-pump coronary artery bypass surgery can be performed with acceptable mortality and morbidity rates in diffuse coronary artery disease.

Key words: coronary endarterectomy, diffused coronary artery disease, off-pump 


\section{GíRiş}

Atan kalpte koroner arter bypass cerrahisi (AKKABC) kardiyopulmoner bypassın (KPB) geliştirilmesi öncesine dayanmaktadır. Fakat KPB'nin icadıyla birlikte unutulmaya yüz tutan teknik, KPB'nin yan etkileri ortaya çıkınca yeniden gündeme gelmiştir. $(1,2,3)$ Ekstracorporeal dolaşım ve kros klemp uygulamasının inflamatuar yanıt aktivasyonu mikroembolizasyon, makroembolizasyon sonucu nörolojik renal ve gastrointestinal disfonksiyon ile birlikte miyokardiyal iskemi reperfüzyon hasarı gibi kötü etkileri bulunmaktadır.(4) AKKABC tüm bu zararlı etkilerden hastayı koruduğu ve postoperatif morbidite, yoğun bakım ve hastane kalış süresi ve operasyon maliyetlerini azalttığı için önerilmektedir.(5) KPB ile veya atan kalpte endarterektomi başka bir yolla, opere edilemeyeceğini düşündügüüüz damarları revaskülarize etmemize yardımcı olur. AKKABC cerrahisi, özellikle yeni geliştirilen cihazlar yardımıyla daha güvenli hale gelmiştir.(6) 1957 yllında koroner endarterektomi (KE), koroner arter hastalığının tedavisinde kardiyopulmoner bypass veya koroner arter bypass cerrahisi (KABC)'den bağımsız bir metot olarak tanımlandı.(7) AKKABC cerrahisinde KE'nin sonuçları cesaret verici olup KPB kullanıldığı klasik KE ile karşılaştırılabilir niteliktedir. Ayrıca çeşitli serilerde gösterildiği gibi KE atan kalp teknikle güvenli bir şekilde yapılabilmektedir.(8)

$\mathrm{KPB}$ eşliğinde yapılan KABC'de KE uygulaması pratikte daha kolaydır. Endarterektomi, yaygın damar tıkanıklığı tespit edilen olgularda önceden planlanan bir işlem olmakla birlikte bazı olgularda daha önceden belirlenmeden yapılmak zorunda da kalınabilir. Koroner arteriyotomi yapıldıktan sonra plak kalkması, yeterli damar lümeninin olmadığının görülmesi üzerine endarterektomi kararı verilir ve yapilır.

$\mathrm{Bu}$ çalışmada amacımız, AKKABC yöntemiyle ameliyat edilen ve KE uygulanan olguların postoperatif uzun dönem sonuçlarını ortaya koymaktır.

\section{YÖNTEM ve GEREÇ}

Kartal Koşuyolu Yüksek İhtisas Eğitim ve Araştırma Hastanesi'nde Kasim 1996'den Haziran 2006'ya kadar geçen sürede, endarterektomi uygulanmış Off-pump koroner bypass cerrahisi uygulanan toplam 48 hasta dahil edildi. Aynı dönemde gerçekleştirilen endarterektomi ile KPB altında koroner cerrahisi uygulanan 528 hasta ve herhangi bir nedenle Off-pump cerrahisi olarak başlanmasına rağmen KPB’a geçilerek operasyona devam edilmek zorunda kalınan hastalar çalışma dışı bırakıldı. Hastaların preoperatif ve postoperatif bilgileri hastane veri tabanı ve hasta kayitlarından topland. Telefon ile ulaşılan hastalar kontrol amacıyla hastaneye davet edildi. Telefon aracılığı ile 2006 Eylül ayına kadar ulaşılan hastaların son durumları ile ilgili veriler toplandı. Kontrol anjiyografisi yapılmamış olan ve kardiyak yakınmaları olan hastalar ile kontrol olmak isteyen hastalar merkezimize davet edilerek tekrar ayrıntılı kontrolden geçirildi. Retrospektif olarak incelenen bu olguların 12'sine kontrol anjiyografisi uyguland.

\section{Ameliyat Tekniği ve Protokol}

Hastalarımız, kliniğimizin rutin koroner arter bypass cerrahisi hazırlığına tabi tutuldu. Tüm hastalarımıza intravenöz narkotik anestezi tekniği ile anestezi uygulandi. Medyan sternotomi sonrasinda sol mammarian arter (LIMA), radiyal arter ve safen ven greftleri hazırlandi.

AKKABC uygulanan hastalarımızda ise greftlerin hazırlanması ve heparinizasyon (Aktive Pıhtılaşma Zamanı $>200$ saniye olacak kadar) işlemlerini takiben anastomozlara geçildi. Bu sırada kalp atım hızını azaltmak için beta-bloker ya da Ca- kanal blokerleriyle medikasyon uyguland. Böylece kardiyak metabolizmanın yavaşlatılması, oksijen tüketiminin azaltılması, koronerlerin perfüzyonunun daha iyi sağlanması ve cerrahi konforun arttırılması amaçland. Distal anastomozlar uygulanırken genel olarak ilk önce sol inen koroner arter (LAD) kanlandırıldı. Böylece kalbin arka-lateral yüzüne ulaşmak için yapılacak manipülasyonlar sırasında koroner perfüzyonun yeterli düzeyde olması sağlandı. Hiçbir hastada intrakoroner şant kullanılmadı. LAD distal anastomozu sırasında kalbin perikart içine yerleştirilen spançlarla pozisyonlandırılması yeterli oldu, anastomoz sahası ise lokal stabilizatör (Genzyme Immobilizer ${ }^{\varpi}$ ) cihazı kullanılarak stabilize edildi. Anastomozlar yapılırken ilk önce pediküllü greftler, daha sonra serbest greftler kullanıldı. Böylelikle distal anastomozun bitimiyle birlikte hedef damarın kanlandırılması sağlandı. Sağ koroner arter (RCA) ve sirkumfleks (Cx) sistemine yapilan distal anastomozlar için kalbe pozisyon veren (Genzyme Positioner $^{\circledast}$ ) cihazlardan yararlanıldı. Derin perikardiyal askı sütürü kullanılmasına ihtiyaç duyulmadı. Sağ mammarian arter (RİMA) gerginliğini azaltmak dışında, kalbi pozisyonlandırmak için sağ plevranın açılması yöntemine başvurulmadı. LAD için olduğu gibi, anastomoz sahası lokal stabilizatör cihazı kullanılarak stabilize edildi. Anastomoz sahasının daha iyi görülebilmesi için üf- 
leme sistemi rutin olarak kullanıldı. Radiyal arterin ve safen ven greftinin proksimal anastomozu side-klempte asendan aort üzerine yapıldı. Daha sonra kanama kontrolü sağlandı, sternum kapatılarak hastalar yoğun bakıma alındı.

KE işlemi bir grup hastada $<2 \mathrm{~cm}$ insizyon kullanılarak pull-out yöntemi (9) ile yapıldı. Bir findık boyutunda şekil verilip alet ucuna takılan cerrahi tampon ile yapilan ters traksiyon kuvveti yardımıyla plak koroner dışına çekildi. Plağın kopması veya dışarı çekilemeyen hastalarda açık endarterektomi yöntemi kullanıldı. Arteriyotomi $2 \mathrm{~cm}$ 'in üzerine çıkılan bu hastalarda LAD sahasında LIMA patch plasti diğer koroner arterlerde safen ven patch plasti uygulandi. Postoperatif takipte drenaj fazla miktarda olmadıkça, protamin uygulanmasından kaçınıldı, önce 3 gün heparin, daha sonra tüm hastalara oral randomize $2,5 \mathrm{mg}$ warfarin ve 150 mg aspirin uygulanarak antikoagülasyon ve antiagregasyon sağlandı. Altı ay sonra warfarin kesilerek aspirin ile tedaviye devam edildi. Postoperatif yoğun bakım takibi sırasında yine tam bir monitorizasyon sağlandı. Drenaj miktarı son 6 saatte toplam 50 mlye düşen hastaların drenleri çıkarıldı. Hastalar yoğun bakım sonrası ara yoğun bakım ve servis izlemlerini takiben taburcu edildiler. Postoperatif 10. gün ve 2 . ayda kontrole çağrıldılar ve daha sonraki takipleri de 6 aylık dönemler seklinde düzenlendi.

\section{İSTATİSTIKKSEL DEĞERLENDİRMELER}

Çalışmada elde edilen bulgular değerlendirilirken, istatistiksel analizler için SPSS (Statistical Package for Social Sciences) for Windows 10.0 programı kullanıldı. Çalışma verileri değerlendirilirken tanımlayıcı istatistiksel metodların (Ortalama, Standart sapma) yanı sıra niceliksel verilerin karşılaştırılmasında normal dağılım gösteren parametrelerin gruplar arası karşılaştırmalarında Oneway Anova testi ve farklılığa neden çıkan grubun tespitinde Tukey HDS testi kullanıldı. Normal dağılım göstermeyen parametrelerin gruplar arası karşılaştırmalarında Kruskal Wallis testi kullanıldı.

\section{BULGULAR}

Hastaların ortalama yaşları $58,8 \pm 9,8$ yıl ve $44(\% 91,7)$ 'ü erkek hastaydı. Hastaların başlıca preoperatif özellikleri Tablo 1'de gösterilmiştir. 48 olguda toplam 48 koroner artere KE uygulandi. Hastaların 7'sine (\%15) tamamen arteriyel revaskülarizasyon uyguland, KE uygula- nan $19(\% 40)$ hastaya uzun arteriyotomi (anastomoz uzunluğu $>20 \mathrm{~mm}$ ) ile birlikte KE uygulandı. Açık EA bu hastaların 14'ünde (\%74) LAD ye, 5 (\%26) hastada RCA'ya uygulandı. Hastaların 30'unda (\%62) komplet revaskülarizasyon uygulanmış olup, endarterektomi yapılan damarlar, kullanılan greftler, anastomoz uzunlukları ve bypass yapılan damar sayıları Tablo 2' de gösterilmiştir. Operasyon sonrası dönemde hastalar ortalama $11 \pm 6$ saatte solunum cihazından ayrıldı. Üç $(\% 6,3)$ hasta kanama nedeniyle revizyona alındı ve perioperatif dönemde 2 hasta $(\% 4,2)$ perioperatif miyokart enfarktüsü (ME) görüldü ve bu hastalara İntraaortik Balon Pompası (İABP) desteği sağlandı. Ortalama 2,29 $\pm 1,27$ gün yoğun bakım ünitesinde kalan hastalar ortalama $9 \pm 6$ günde taburcu oldu. Operasyon sonrası hastaların özellikleri Tablo 3' te gösterilmiştir. Hastalara kontrol koroner anjiyografi ortalama $27.2 \pm$ 18,32 ayda yapıld1, bu hastaların sadece 2 'inde Kanada Kalp Derneği Anjina Sınıflamasına (KKDS) göre Klas 3 şikâyeti mevcuttu, diğer 9 hastada Klas1 semptomları olduğu görüldü. Kontrol anjiyografi sonucuna göre 20 anastomoz edilen greftten 3'ü (\%15) tıkalı olarak, saptand. Bu 3 greft EA yapılan damarlardı. Endarterektomi yapılan damarların $(\mathrm{n}=12)$ açıklık oranı da $\% 75$ olarak saptandi. Kontrol koroner anjiyografi sonuçları ve tüm hastaların postoperatif anjinal şikayetler Tablo 4'de görülmektedir. Hastaların 3'nde $(\% 6,3)$ erken mortalite görüldü, ortalama $117 \pm 4,65$ ay takip süresi boyunca geç mortalite gözlenmedi.

\section{TARTIŞMA}

Cerrahi teknikler içinde KE, 1957 yılında Bailey (10) tarafindan ilk defa uygulanmasindan sonra son 2030 yıldır tekrar önem kazanmış, ve birçok merkez tarafından kullanılmaya başlanmıştır. İlk sonuçlar pek yüz güldürücü olmamakla birlikte tatminkâr sonuçlar $\mathrm{KE}, \mathrm{KABG}$ ile birlikte kombine edilince alınmaya başlanmıştır.

Koroner endarterektominin en büyük avantajı, yaygın damar hastalarında, geleneksel greftleme yöntemleriyle açılamayan yan dalların açılmasıyla miyokardın iskemiden kurtarılmasıdır. İnkomplet revaskülarizasyon erken ve geç mortaliteyi etkileyen en önemli faktörlerdendir.(11) Son yıllardaki gelişmelerle fokal ve lokalize lezyonlu koroner arter hastalığında perkütan koroner girişim ilk tercih edilen tedavi işlemi haline gelmiştir.(12) Yaygın ve çok damar hastalığı bulunan sol ventrikül fonksiyonları gerilemiş hasta- 
Tablo 1: Preoperatif Hasta Özellikleri

\begin{tabular}{|ll|}
\hline Değişkenler & N $(\%) /($ OrttSD) \\
\hline Yaş (yıl) & $58,8 \pm 9,8$ \\
\hline Cinsiyet & \\
\hline Erkek & $44(\% 91,7)$ \\
\hline Kadın & $4(\% 8,3)$ \\
\hline Sigara & $40(\% 83,3)$ \\
\hline DM & $16(\% 33,3)$ \\
\hline Hiperlipidemi & $16(\% 33,3)$ \\
\hline Hipertansiyon & $25(\% 52,1)$ \\
\hline Aile öyküsü & $26(\% 54,2)$ \\
\hline Geçirilmiş ME & $32(\% 66,7)$ \\
\hline KKD Anjina Kalsifikasyonu \\
\hline Klass 1 & $1(\% 2,1)$ \\
\hline Klass 2 & $23(\% 48)$ \\
\hline Klass 3 & $10(\% 21)$ \\
\hline Klass 4 & $14(\% 29)$ \\
\hline PAH & $6(\% 12,5)$ \\
\hline KOAH & $2(\% 4,2)$ \\
\hline SAK & $6(\% 12,5)$ \\
\hline SVEF \% & $28(\% 58)$ \\
\hline$>$ < $\% 50$ & \\
\hline$<50$ & \\
\hline
\end{tabular}

*SD: Standart sapma, DM: Diyabetis Mellitus, ME: Miyokart Enfarktüsü, KKD: Kanada Kalp Derneği Anjina Sınıflaması, PAH: Periferik arter hastalığı, KOAH: Kronik Obstriktif Akciğer Hastalığı, SAK: Sol Ana Koroner Arter, SVEF: Sol Ventrikül Ejeksiyon Fraksiyonu lar hala KABG ile tedavi edilmektedir.(13) Günümüzde artan koroner arter hastalığı sayıları ile birlikte AKKABC daha çok hastada uygulanması, AKKABC ile birlikte uygulanan KE’nin sonuçlarını yeniden değerlendirme ihtiyacı doğurmaktadır. Özellikle yüksek riskli hasta grubunda AKKABC yaygın bir şekilde kullanılmaktadır. KPB da görülen renal, nörolojik ve inflamatuar yan etkilerin daha az görüldüğü bilinmektedir.(4,5) Günümüzde ise selektif olarak seçilen hastalarda KE kabul edilebilir operatif risk ve iyi uzun dönem sonuçları ile yapılabilmektedir. $(14,15)$ AKKABC cerrahi sonuçları Eryılmaz ve arkadaşlarının(8) daha küçük olan serilerinde $(n=11)$ mortalite oranı \%0 bildirilirken, Vohra ve ark.(16) 70 hastalık serilerinde bu oran \%2,8 olarak bildirilmiştir. Bizim serimizde erken mortalite $\% 6,3$ olarak bulunmuş olmasına rağmen Vohra ve ark. serilerinde LAD'ye yapılan EA oranı sadece \%17 iken bu oran bizim serimizde $\% 60$ 'dır. Özellikle LAD ye yapılan uygun revaskülarizasyon hastanın prognozunda en önemli belirleyicilerdendir $(17,18)$, bununla birlikte LAD'ye yapılan EA'nin mortaliteyi arttırdığını bildiren yayınlar mevcutken (mortalite oranı \%8,5) (19), daha kabul edilebilir mortalite oranları (\%3)(15) bildiren yayınlar da vardır.

Literatüre baktığımızda koroner endarterektomi için "açık EA tekniği", "traksiyon tekniği” ve "açık EA ve safen patch plasti” gibi birçok tekniğin tarif edildiğini görmekteyiz.(16,20,21) Koroner endarterektomi tekniklerinin mortalite ve morbidite üzerinde anlamlı etkisinin olmadığını gösteren çalışmalar vardır. $(22,23)$ Yine de bu teknikler arasında açık endarterektomi tekniğinin daha güvenli olduğu belirtilmektedir.(15,22) Biz hasta grubumuzda 29 (\%60) hastada sinırlı arteriyotomi ( $<2 \mathrm{~cm}$ ) ile traksiyon yöntemi, $19(\% 40)$ hastada uzun arteriyotomi $(\geq 2 \mathrm{~cm}$ ) ile açık EA uyguladık. Açık EA bu hastaların 14'ünde (\%74) LAD'ye, 5 (\%26) hastada RCA'ya uygulanmıştır. Hasta grubumuzda LAD'ye yapılan anastomozların \%97'sini mammarian arter oluştururken EA yapılan damarlarda safen patch plasti kullanılmadı.

Koroner endarterektomi uygulanan olgularda gözlenen akut greft oklüzyonu sonrası gelişen miyokart enfarktüsü ciddi bir problemdir. Postoperatif ME oranları çeşitli serilerde \%1,5 ile \%13 arası rapor edilmiştir. $(19,21,24)$ Chen ve ark.(25) 92 AKKABC uyguladıkları hasta gruplarını KPB ile opere ettikleri 120 hasta ile karşılaştırmışlar ve postoperatif MI oranın, \%2,8 olarak rapor etmişler ve vohra ve ark.(16) AKKABC uyguladıkları 70 hastalık serilerinde postoperatif ME oranını \%4,3 olarak vermiştir. Bizim olgularımızda postoperatif ME \%4,2 saptanmıştır ve diğer serilerdeki sonuçlarla uyumludur. 
Hastalarımızın $117 \pm 4,65$ ay takip süresi boyunca yapılan kontrolleri sırasinda \%14,5 hastada tekrar anlamlı anjina şikâyeti saptadık. Gill ve ark.(26) 36₫16 aylık takipte hastalarını \%14'ünde tekrar anjina şikayeti saptamışlar. Christakis ve ark.(27) 5 yıllık takip sonucu hastalarının ancak \%35'inde anjina saptamışlardır. Vohra ve ark.(16) 4,6 yıl takip süresinde hastalarının \%90'ında anjina görmemişler ve anjina semptomlarının tekrarlanmasındaki bu farkın, yerel popülasyonda mevcut olan koroner hastalığın özellikle farklı doğasından veya uygulanan yetersiz revaskülarizasyondan kaynaklanabileceği yorumunu yapmışlar.

Bu çalışma kliniğimizin 1996-ve 2006 yıllarında gerçekleştirilen hastaları kapsamaktadır. Akut greft ve nativ damar trombozunu engellemek için postoperatif erken dönem tüm hastalara intravenöz heparin tedavisi başlanmıs olup daha sonra takibinde 6 ay boyunca warfarin tedavisi verilmiştir. Güncel uygulamamız birçok çalışmada olduğu gibi 6 ay boyunca aspirin ve klopidogrel antiagregan tedavisi başlayıp daha sonra aspirin ile tedaviye devam etmek şeklindedir. $(28,29)$

Hasta grubumuzda ortalama $27.2 \pm 18,32$ takip süresi boyunca toplam 12 hastaya kontrol koroner anjiyografi yapılmıştır. 20 anastomoz edilen greftten 3 '̈u (\%15) tıkalı olarak saptandı. Bu 3 greft EA yapılan damarlardı. LAD'ye yapılan greftlerin \%91,7 si RCA'ya yapilan greftlerin \%71,4'ünün açık olduğu görülmüş olup toplam açıllık oranı \%85 olarak saptanmıştır. LAD’ye EA uygulanan tüm hastalarda internal mammarian arter greft olarak kullanılmıștır. Beretta ve ark. safen ven yerine LIMA kullanılan hastalarda perioperatif ME oraninda \%10'dan \%2'ye, greft açılılı oranlarında \%85'ten \%93'e, 5 yıllık hayatta kalım oranlarında ise $\% 70$ 'ten $\% 87$ ye yükseldiğini tespit etmişlerdir.(30) Eryılmaz ve ark.(8) 1 yıllık toplam açıklık oranı olarak \%95.6 vermişlerdir. Her ne kadar hasta grubumuzda kontrol anjiyografi yapilan hasta sayısı (\%25) yeterli olmasa da uzun takip süresinde saptanan açıklık oranları diğer serilerle benzerlik göstermektedir.

\section{SONUÇ}

Çalışmada sınırlı sayıda hasta bulunsa da uzun dönem takibi yapilan bu hasta serisinde koroner endarterektomi ile birlikte atan kalpte koroner bypass operasyonunun tecrübeli ellerde kabul edilebilir mortalite ve morbidite oranları ile yapılabileceği anlaşılmaktadır.
Tablo 2: Endarterektomi Yapılan Damarlar ve Operatif Özellikler

\begin{tabular}{|c|c|}
\hline Değişkenler & $\mathbf{N}(\%)$ \\
\hline \multicolumn{2}{|l|}{ Endarterektomi yapılan damarlar } \\
\hline$L A D$ & $29(\% 60)$ \\
\hline$D 1$ & $1(\% 2,1)$ \\
\hline$C x$ & $1(\% 2,1)$ \\
\hline$R C A$ & $17(\% 35)$ \\
\hline LAD'ye kullanılan greft & $48(\% 100)$ \\
\hline LIMA & $41(\% 85)$ \\
\hline RIMA & $4(\% 8)$ \\
\hline Safen ven & $3(\% 6,3)$ \\
\hline Diyagonal 'e kullanılan greft & $4(\% 100)$ \\
\hline Safen ven & $4(\% 100)$ \\
\hline Sirkumfleks 'e kullanılan greft & $13(\% 100)$ \\
\hline LIMA & $4(\% 30)$ \\
\hline Radiyal arter & $2(\% 15)$ \\
\hline Safen ven & $7(\% 55)$ \\
\hline RCA 'ya kullanılan greft & $26(\% 100)$ \\
\hline RIMA & $3(\% 11)$ \\
\hline Radial arter & $7(\% 27)$ \\
\hline Safen ven & $16(\% 61)$ \\
\hline TAR & $7(\% 15)$ \\
\hline \multicolumn{2}{|l|}{ Uzun segment anastomoz } \\
\hline$\geq 2$ & $19(\% 39,6)$ \\
\hline$<2$ & $29(\% 60,4)$ \\
\hline 1 Damar KABG & $14(\% 29)$ \\
\hline 2 Damar KABG & $22(\% 46)$ \\
\hline 3 Damar KABG & $11(\% 23)$ \\
\hline 4 Damar KABG & $1(\% 2,1)$ \\
\hline
\end{tabular}

*LAD: Sol ön inen arter, D1: 1.diagonal arter, Cx: Sirkumfleks arter, RCA: Sağ koroner arter, LiMA: Sol Internal Mamarian Arter RiMA: Sağ Internal Mamarian Arter, TAR: Tamamen Arteriyel Revaskülarizasyon, KABG: Koroner Arter Bypas Greftleme Cerrahisi 
Tablo 3: Postoperatif Hasta Özellikleri ve Sonuçlar

\begin{tabular}{|ll|}
\hline Değ işkenler & N $(\%) /($ OrttSD) \\
\hline CK & $539 \pm 353$ \\
\hline CKMB & $33 \pm 28$ \\
\hline Ekstübasyon zamanı (saat) & $11 \pm 6$ \\
\hline Drenaj Miktarı (cc) & $836 \pm 480$ \\
\hline Eritrosit Kullanımı (ünite) & $1,21 \pm 1,35$ \\
\hline Perioperatif ME & $2(\% 4,2)$ \\
\hline Geçici AF & $4(\% 8,3)$ \\
\hline Pozitif Inotrop kullanımı & $4(\% 8,3)$ \\
\hline IABP Kullanımı & $2(\% 4,2)$ \\
\hline Revizyon & $3(\% 6,3)$ \\
\hline YBÜ' de kalış (gün) & $2,29 \pm 1,27$ \\
\hline Hastanede Kalış (gün) & $9 \pm 6$ \\
\hline Komplet Revaskülarizasyon & $30(\% 62)$ \\
\hline
\end{tabular}

${ }^{*} C K$ : Kreatin kinaz, CKMB: Kreatin kinaz MB, ME: Miyokart Enfarktüsü, AF: Atriyal Fibrilasyon, IABP: Intraaortik balon pompası, YBÜ: Yoğun Bakım Ünitesi

Tablo 4: Kontrol Anjiyografi Sonuçları ve Postoperatif Hastaların Şikayetleri

\begin{tabular}{|c|c|}
\hline \multicolumn{2}{|c|}{ Damarların Açıklık Oranı } \\
\hline ve Anjine Şikâyeti & $\mathrm{N}(\%)$ \\
\hline LAD & $12(\% 100)$ \\
\hline Açık & $11(\% 91,7)$ \\
\hline Tıkalı & $1(\% 8,3)$ \\
\hline$C X$ & $1(\% 100)$ \\
\hline Açık & $1(\% 100)$ \\
\hline Tikalı & 0 \\
\hline RCA & $7(\% 100)$ \\
\hline Açık & $5(\% 71,4)$ \\
\hline Tikalı & $2(\% 28,6)$ \\
\hline \multicolumn{2}{|l|}{ KKDS } \\
\hline Klass 1 & $41(\% 85,5)$ \\
\hline Klass 2 & $1(\% 2)$ \\
\hline Klass 3 & $6(\% 12,5)$ \\
\hline Klass 4 & - \\
\hline
\end{tabular}

LAD: Sol ön inen arter, Cx: Sirkumfleks arter, RCA:

Sağ koroner arter, KKDS: Kanada Kalp Derneği Anjina Sınıflaması

\section{Destek ve Teșekkür:}

Koşuyolu Yüksek İhtisas Kalp Eğitim ve Araştırma Hastanesi'nde çalıştığım dönemde gerek çalışmaya yaptıkları katkılar gerekse verdikleri eğitimden dolayı başta tez danışmanım Prof. Dr. Kaan Kırali'ye ve Prof. Dr. Denyan Mansuroğlu, Prof. Dr. Suat Nail Ömeroğlu, Prof. Dr. Mete Alp, Prof. Dr. Rahmi Zeybek, Prof. Dr. Gökhan İpek, Prof. Dr. Mustafa Güler, Doç. Dr Mehmet Balkanay ve Prof. Dr Cevat Yakut Hocalarıma teşekkür ederim.

Received Date/Geliş Tarihi: 22.06.2020

Accepted Date/Kabul Tarihi: 13.07.2020

\section{REFERANSLAR}

1. Favaloro RG, Effler DB, Groves LK, Sheldon WC, Sones FM. Direct Myocardial Revascularization by Saphenous Vein Graft: Present Operative Technique and Indications. Ann Thorac Surg [Internet]. 1970;10(2):97-111.

2. Trapp WG, Bisarya R. Placement of Coronary Artery Bypass Graft Without Pump Oxygenator. Ann Thorac Surg [Internet]. 1975;19(1):1-9.

3. Benetti FJ, Naselli G, Wood M, Geffner L. Direct myocardial revascularization without extracorporeal circulation; Experience in 700 patients. Chest [Internet]. 1991;100(2):312-6.

4. Raja SG, Dreyfus GD. Current status of off-pump coronary artery bypass surgery. Asian Cardiovasc Thorac Ann. 2008;16(2):164-78.

5. Angelini GD, Culliford L, Smith DK, Hamilton MCK, Murphy GJ, Ascione R, et al. Effects of on- and off-pump coronary artery surgery on graft patency, survival, and health-related quality of life: Long-term follow-up of 2 randomized controlled trials. J Thorac Cardiovasc Surg [Internet]. 2009;137(2):295-303.e5.

6. Mishra M, Malhotra R, Mishra A, Meharwal ZS, Trehan N. Hemodynamic changes during displacement of the beating heart using epicardial stabilization for off-pump coronary artery bypass graft surgery. J Cardiothorac Vasc Anesth. 2002;16(6):685-90.

7. Effler Db, Groves Lk, Sones Fm, Shirey Ek. Endarterectomy in the Treatment of Coronary Artery Disease. J Thorac Cardiovasc Surg [Internet]. 1964;47(1):98108.

8. Eryilmaz S, Inan MB, Eren NT, Yazicioglu L, Corapcio®lu T, Akalin H. Coronary endarterectomy with off-pump coronary artery bypass surgery. Ann Thorac Surg. 2003;75(3):865-9.

9. Sareyyüpoğlu B, Yıldırım Ö, Kırali K. Different Results of Proximal Coronary Endarterectomy via Conventional Pull-Out Method. Kosuyolu Hear J. 2012;15(2):90-1.

10. Bailey CP, May A, Francisco S, Lemmon WM. gradually enlarging. 2016;

11. Lawrie GM, Morris GC, Silvers A, Wagner WF, Baron AE, Beltangady SS, et al. The influence of residual disease after coronary bypass on the 5 -year survival rate of 1274 men with coronary artery disease. Circulation. 1982;66(4 I):717-23.

12. Erratum: 2012 ACCF/AHA/ACP/AATS/PCNA/SCAI/STS guideline for the di- 
agnosis and management of patients with stable ischemic heart disease: Circulation. 2014;129(16):2014.

13. ElBardissi AW, Balaguer JM, Byrne JG, Aranki SA. Surgical Therapy for Complex Coronary Artery Disease. Semin Thorac Cardiovasc Surg [Internet] 2009;21(3):199-206

14. Tiruvoipati R, Loubani M, Peek G. Coronary endarterectomy in the current era Curr Opin Cardiol. 2005;20(6):517-20.

15. Byrne JG, Karavas AN, Gudbjartson T, Leacche M, Rawn JD, Couper GS, et al. Left anterior descending coronary endarterectomy: Early and late results in 196 consecutive patients. Ann Thorac Surg. 2004;78(3):867-73.

16. Vohra HA, Kanwar R, Khan T, Dimitri WR. Early and Late Outcome After OffPump Coronary Artery Bypass Graft Surgery With Coronary Endarterectomy: A Single-Center 10-Year Experience. Ann Thorac Surg. 2006;81(5):1691-6.

17. Cukingnan RA, Carey JS, Wittig JH, Brown BG. Influence of complete coronary revascularization on relief of angina. J Thorac Cardiovasc Surg [Internet] 1980;79(2):188-93.

18. Gkiousias V, Stavrou A, Kyprianou K, Dimitrakaki IA, Challoumas D, Dimitrakakis G. Coronary endarterectomy: The current state of knowledge. Atherosclerosis [Internet]. 2016;249(October 1956):88-98.

19. Livesay JJ, Cooley DA, Hallman GL, Reul GJ, Ott DA, Duncan JM, et al. Early and late results of coronary endarterectomy: analysis of 3,369 patients. J Thorac Cardiovasc Surg [Internet]. 1986;92(4):649-60.

20. Ladowski JS, Schatzlein MH, Underhill DJ, Peterson AC. Endarterectomy, vein patch, and mammary bypass of the anterior descending artery. Ann Thorac Surg [Internet]. 1991;52(5):1187-9.

21. Tasdemir O, Kiziltepe U, Karagoz HY, Yamak B, Korkmaz S, Bayazit K. Longterm results of reconstructions of the left anterior descending coronary artery in diffuse atherosclerotic lesions. J Thorac Cardiovasc Surg. 1996;112(3):745-54.
22. Sirivella S, Gielchinsky I, Parsonnet V. Results of coronary artery endarterectomy and coronary artery bypass grafting for diffuse coronary artery disease. Ann Thorac Surg. 2005;80(5):1738-44.

23. Ferraris VA, Harrah JD, Moritz DM, Striz M, Striz D, Ferraris SP. Long-term angiographic results of coronary endarterectomy. Ann Thorac Surg. 2000;69(6):173743.

24. Brenowitz JB, Kayser KL, Johnson WD. Results of coronary artery endarterectomy and reconstruction. J Thorac Cardiovasc Surg [Internet]. 1988;95(1):1-10.

25. Qiu Z, Chen X, Jiang Y, Wang L, Xu M, Huang F, et al. Comparison of off-pump and on-pump coronary endarterectomy for patients with diffusely diseased coronary arteries: Early and midterm outcome. J Cardiothorac Surg. 2014;9(1):1-8.

26. Gill IS, Beanlands DS, Boyd WD, Finlay S, Keon WJ. Left anterior descending endarterectomy and internal thoracic artery bypass for diffuse coronary disease. Ann Thorac Surg. 1998;65(3):659-62.

27. Christakis GT, Rao V, Fremes SE, Chen E, Naylor CD, Goldman BS. Does Coronary Endarterectomy Adversely Affect the Results of Bypass Surgery? J Card Surg. 1993;8(1):72-8.

28. Ariyaratnam P, Javangula K, Papaspyros S, McCrum-Gardner E, Nair RU. Longterm survival from 801 adjunctive coronary endarterectomies in diffuse coronary artery disease. Eur J Cardio-thoracic Surg. 2012;42(6):140-5.

29. Nishigawa K, Fukui T, Yamazaki M, Takanashi S. Ten-Year Experience of Coronary Endarterectomy for the Diffusely Diseased Left Anterior Descending Artery. Ann Thorac Surg [Internet]. 2017;103(3):710-6.

30. Beretta L, Lemma M, Vanelli P, DiMattia D, Bozzi G, Broso P, et al. Coronary "open" endarterectomy and reconstruction: Short- and long-term results of the revascularization with saphenous vein versus IMA-graft. Eur J Cardio-thoracic Surg. 1992;6(7):382-7. 